\begin{tabular}{|c|c|}
\hline Uniqbu Journal of Social Sciences (UJSS) \\
E-ISSN: 2723-3669
\end{tabular}

\title{
PERAN KEPEMIMPINAN KEPALA SEKOLAH DALAM MENERAPKAN MANAJEMEN MUTU PENDIDIKAN
}

\section{(The Leadership Role of the Principal in Implementing Education Quality Management)}

\author{
Dr. ${ }^{1 *}$ Al Akbar, ${ }^{2}$ Hastuti, ${ }^{3}$ Suwardi Annas, ${ }^{4}$ Muh. Yahya \\ ${ }^{1}$ SMP Negeri 2 Arungkeke, Jeneponto, Indonesia \\ ${ }^{2}$ Universitas Negeri Makassar \\ ${ }^{3}$ Pascasarnajana STKIP Pembangunan Indonesia Makassar, Indonesia \\ ${ }^{4}$ Pendidikan Ekonomi STKIP Pembangunan Indonesia, Makassar Indonesia \\ Email: akbarzn@gmail.com
}

(Received 20 December; Revised 29 December; Accepted 30 December 2022)

\begin{abstract}
This study aims to describe: 1) The role of the principal in implementing education quality management at SMP Negeri 2 Arungkeke, Jeneponto Regency, 2) Supporting and inhibiting factors for the principal in implementing education quality management at SMP Negeri 2 Arungkeke, Jeneponto Regency. The type of research used is descriptive qualitative research. Qualitative research is a research approach that uncovers certain social situations by properly describing reality, formed by words based on relevant data collection and analysis techniques obtained from natural situations. Sources of data in this study, namely data that shows the quality or quality of something that exists, in the form of circumstances, processes, events or events and others expressed in the form of words. The informants in the study were the principal, social studies teacher for class IX, and social studies teacher for class VII/VIII, English teacher and staff of SMP Negeri 2 Arungkeke. The technique of determining the informant was carried out purposively, namely based on the capacity that provided convenience and willingness in the interview. The results of this study indicate that 1) the leadership role of the principal in implementing education quality management in SMP Negeri 2 Arungkeke, namely: (a) the principal must have the right strategy and (b) apply leadership management. 2) Supporting and inhibiting factors for school principals in implementing education quality management at SMP Negeri 2 Arungkeke, namely: supporting factors (a) mutual cooperation and kinship (b) providing opportunities for teachers in professional application training activities (c) facilitating all school activities, factors inhibiting (a) lack of motivation and enthusiasm of the principal (b) lack of leadership ability of the principal (c) lack of facilities and infrastructure and $(d)$ low mental attitude.
\end{abstract}

Keywords: Principal Leadership and Education Quality Management

\section{Abstrak}

Penelitian ini bertujuan untuk mendeskripsikan: 1) Peran kepala sekolah dalam menerapkan manajemen mutu pendidikan di SMP Negeri 2 Arungkeke, Kabupaten Jeneponto, 2) Faktor pendukung dan penghambat kepala sekolah dalam menerapkan manajemen mutu pendidikan di SMP Negeri 2 Arungkeke, Kabupaten Jeneponto. Jenis penelitian yang digunakan adalah penelitian deskriptif kualitatif. Penelitian kualitatif adalah suatu pendekatan penelitian yang mengungkap situasi sosial tertentu dengan mendeskripsikan kenyataan secara 
benar, dibentuk oleh kata-kata berdasarkan teknik pengumpulan dan analisis data yang relevan yang diperoleh dari situasi yang alamiah. Sumber data pada penelitian ini, yaitu data yang menunjukkan kualitas atau mutu dari sesuatu yang ada, berupa keadaan, proses, kejadian atau peristiwa dan lain-lain yang dinyatakan dalam bentuk perkataan. Informan dalam penelitian adalah kepala sekolah, guru IPS kelas IX, dan Guru IPS kelas VII/VIII, guru Bahasa Inggris dan Staft SMP Negeri 2 Arungkeke. Teknik penentuan informan dilakukan secara purposive yakni berdasarkan kapasitas yang memberikan kemudahan dan kesediaan dalam wawancara. Hasil penelitian ini menunjukkan bahwa 1) peran kepemimpinan kepala sekolah dalam menerapkan manajemen mutu pendidikan di SMP Negeri 2 Arungkeke, yaitu : (a) kepala sekolah harus memiliki strategi yang tepat dan (b) menerapkan manajemen kepemimpinan. 2) Faktor pendukung dan penghambat kepala sekolah dalam menerapkan manajemen mutu pendidikan di SMP Negeri 2 Arungkeke yaitu : faktor pendukung (a) gotong royong dan kekeluargaan (b) memberikan kesempatan kepada guru dalam kegiatan diklat penerapan profesi (c) memfasilitasi segala kegiatan sekolah, faktor penghambat (a) kurangnya motivasi dan semangat kepala sekolah (b) kurangnya kemampuan kepemimpinan kepala sekolah (c) kurangnya sarana dan prasarana dan (d) rendahnya sikap mental.

Kata Kunci: Kepemimpinan Kepala Sekolah dan Manajemen Mutu Pendidikan

\section{PENDAHULUAN}

Sejalan dengan tantangan kehidupan global, pendidikan merupakan hal yang sangat penting karena pendidikan salah satu penentu mutu sumber daya manusia. Dewasa ini keunggulan suatu bangsa bukan lagi diidentikkan dengan melimpahnya ruang kekayaan alam yang ada, akan tetapi lebih kepada keunggulan sumber daya manusianya, sebab mutu sumber daya manusia berkontribusi bagi mutu pendidikan. Mutu secara umum adalah gambaran dan karakteristik menyeluruh dari barang atau jasa yang menunjukkan kemampuannya dalam memuaskan yang diharapkan atau yang tersirat. Kontek pendidikan memberikan pengertian mengenai mutu pendidikan yaitu mencakup pada input, proses dan output pendidikan (Depdiknas, 2001)

The Greek government, in Mutu pendidikan merupakan salah satu isu dalam pendidikan, terutama berkaitan dengan rendahnya mutu pendidikan pada setiap jenjang dan satuan pendidikan, khususnya pendidikan dasar atau pendidikan menengah. Menyadari hal tersebut pemerintah melakukan berbagai upaya untuk meningkatkan mutu pendidikan, antara lain melalui berbagai pelatihan dan peningkatan mutu kompetensi guru, pengadaan buku dan media pembelajran, perbaikan sarana dan prasarana pendidikan, serta peningkatan mutu manajeman sekolah.

Pelaksanaan program pendidikan yang telah dibuat harus secara konsekuen dijalankan tanpa ada penyimpangan, di samping itu memperhatikan faktor efektvitas dan efesiensi, melaksanakan proses belajar mengajar yang efektif misalnya kepala sekolah harus membuat tim kerja yang terdiri dari guru-guru secara profesional dan proporsional (Pamadi, 2001)

Berdasarkan penjelasan di atas, maka kepala sekolah mendapat tuntutan peran yang sangat besar. Kepala sekolah harus kuat dan memiliki gaya kepemimpinan yang kuat untuk mendorong seluruh gurunya bekerja total dalam mendidik siswasiswanya, memiliki visi untuk kemajuan sekolah, konsisten dengan visinya, tapi tetap demokratis dan menghargai pandangan para bawahannya. Kepala sekolah juga harus memiliki ekspektasi yang baik pada para siswanya, misalnya memberikan penguatan keterampilan dasar kepada siswa sehingga bisa berkembang dengan baik dalam proses apapun dan mampu menciptakan suasana 
yang kondusif untuk para guru dan karyawan serta menciptakan suasana yang nyaman untuk guru dan siswa (Rosyada, 2013).

Berbanding terbalik dengan kenyataan di lapangan, masih banyak kepala sekolah yang tidak menjalankan peran, tugas dan fungsinya sebagai pemimpin pendidikan. Hal ini disebabkan karena dalam pengangkatan kepala sekolah seringkali tidak ada transparansi, rendahnya mental kepala sekolah yang ditandai dengan kurangnya motivasi dan semangat kerta kurangnya disiplin dalam melakukan tugas. Maka dapat disimpulkan bahwa peran kepala sekolah pada saat ini belum seperti yang diharapkan.

Peran kepala sekolah akan sangat menentukan maju atau mundurnya pendidkan. Sebab, semua kegiatan dan administrasi, pendidikan, merupakan tanggung jawab kepala sekolah sebagai pemimpin tertinggi.Artinya kepala sekolah memegang peranan penting dalam meningkatkan mutu pendidikan.

\section{METODE PENELITIAN}

Jenis penelitian yang digunakan adalah penelitian deskriptif kualitatif. Penelitian kualitatif adalah suatu pendekatan penelitian yang mengungkap situasi sosial tertentu dengan mendeskripsikan kenyataan secara benar, dibentuk oleh kata-kata berdasarkan teknik pengumpulan dan analisis data yang relevan yang diperoleh dari situasi yang alamiah.

Sumber data pada penelitian kualitatif, yaitu data yang menunjukkan kualitas atau mutu dari sesuatu yang ada, berupa keadaan, proses, kejadian atau peristiwa dan lain-lain yang dinyatakan dalam bentuk perkataan. Dalam penelitian kualitatif sumber data terdiri dari :

a. Data Primer yaitu data yang diperoleh langsung dari informan penelitian melalui teknik wawancara. Adapun yang dijadikan informan dalam wawancara tersebut adalah Kepala Sekolah, Wakil Kepala Sekolah bagian Kurikulum, dan kepala KTU. Beberapa narasumber tersebut diharapkan dapat membantu untuk mendapatkan data mengenai masalah yang diteliti.

b. Data Sekunder dalam penelitian ini berupa dokumentasi, baik berupa naskah-naskah dan beberapa data yang relevan dengan kepemimpinan kepala sekolah di SMP Negeri 2 Arungkeke.

Adapun sumber data yang penulis siapkan yaitu dari informan penelitian atau pelaku yang memahami informasi objek penelitian yakni tenaga pendidik dan tenaga kependidikan serta kepala sekolah SMP Negeri 2 Arungkeke. Penentuan informan dalam penelitian ini dilakukan secara porposive smapling

\section{HASIL DAN PEMBAHASAN}

1. Peran Kepala Sekolah dalam Menerapkan Manajemen Mutu Pendidikan di SMP Negeri 2 Arungkeke, Kab. Jeneponto

a. Strategi yang tepat

Peran kepala dalam menerapkan manajemen mutu pendidikan di SMP Negeri 2 Arungkeke, Kabupaten Jeneponto yaitu pada tahap pertama yakni tahap planning. Dalam tahap tersebut maka fungsi yang terkait dengan hal ini yaitu dengan memanfaatkan sumber daya secara maksimal, efektif dan efesien. Peran pokok 
kepala sekolah dalam menerapkan manajemen mutu pendidikan adalah sebagai berikut :

\section{1) Kepala Sekolah Sebagai Edukator (Guru)}

Dalam melakukan fungsinya sebagai edukator, kepala sekolah harus memiliki strategi yang tepat untuk meningkatkan profesionalisme tenaga pendidikan di sekolahnya. Untuk menciptakan iklim sekolah yang kondusif, kepala sekolah memberikan nasehat kepada warganya di sekolah seperti, memberikan motivasi kepada tenaga kependidikan, memberikan model pembelajaran yang menarik dalam fungsinya sebagai guru.

2) Kepala Sekolah Sebagai Manajer

Dalam rangka melakukan peran dan fungsinya sebagai seorang manajer, kepala sekolah harus memiliki strategi yang tepat untuk memberdayakan tenaga pendidik dan kependidikan melalui kerja sama atau, memberi kesempatan kepada tenaga kependidikan untuk meningkatkan prestasinya, dan mendorong keterlibatan seluruh tenaga kependidikan dalam berbagai kegiatan yang menunjang program di sekolah.

\section{3) Kepala Sekolah Sebagai Administrator}

Kepala sekolah sebagai administrator memiliki hubungan yang sangat erat dengan berbagai aktivitas pengelolaan administrasi yang bersifat pencatatan, penyusunan, dan pendokumentasian seluruh program sekolah. Secara spesifik kepala sekolah harus memiliki kemampuan untuk mengelola kurikulum, mengelola administrasi peserta didik, mengelola administrasi personalia, mengelola administrasi sarana dan prasarana, administrasi kearsipan, dan mengelola administrasi keuangan. b. Menerapkan manajemen kepemimpinan Kepala sekolah di SMP Negeri 2 Arungkeke dalam menerapkan manajemen mutu pendidikan harus menerapkan manajemen kepemimpinan, sebab keberhasilan kepemimpinan kepala sekolah terutama dilandasi oleh kemampuannya dalam memimpin.

1) Kepala Sekolah sebagai Supervisor Kegiatan utama pendidikan di sekolah dalam rangka mewujudkan tujuannya adalah sebagai kegiatan pembelajaran, sehingga seluruh aktivitas organisasi sekolah bermuara pada pencapaian efisiensi dan efektivitas pembelajaran.

2) Kepala Sekolah Sebagai Leader Kepala sekolah sebagai leader dapat dianalisis dari tiga sifat kepemimpinan, yakni demokratis, otoriter, laissez-faire. Sifat tersebut sering dimiliki secara bersamaan oleh seorang leader, sehingga dalam melaksanakan kepemimpinannya sifat-sifat tersebut muncul secara situsional.

3) Kepala Sekolah Sebagai Motivator Kepala sekolah sebagai motivator harus memiliki strategi yang tepat untuk memberikan motivasi kepada para tenaga kependidikan dalam melakukan berbagai tugas dan fungsinya. Motivasi ini dapat ditumbuhkan melalui pengaturan lingkungan fisik, pengaturan suasana kerja, disiplin, dorongan, penghargaan secara efektif, dan penyediaan berbagai sumber belajar melalui pengembangan pusat sumber belajar.

4) Kepala Sekolah Sebagai Inovator Kepala sekolah sebagai inovator akan tercermin dari cara ia melakukan pekerjaanya secara konstruktif, kreatif, delegatif, integratif, rasional dan objektif, pragmatis, keteladanan, disiplin, dan 
fleksibel. Kepala sekolah sebagai innovator harus mampu mencari, menemukan, dan melaksanakan berbagai pembaharuan di sekolah, gagasan baru.

2. Faktor Pendukung dan Penghambat Kepala Sekolah dalam Menerapkan Manajemen Mutu Pendidikan di SMP Negeri 2 Arungkeke, Kab. Jeneponto

Dalam melaksanakan fungsi

kepemimpinannya, kepala sekolah harus melakukan pengelolaan dan pembinaan terhadap seluruh komponen sekolah melalui kegiatan administrasi, manajemen dan kepemimpinan yang sangat tergantung pada kemampuan manajerial seorang kepala sekolah.Sehubungan dengan itu, kepala sekolah sebagai supervisor berfungsi untuk mengawasi, membangun, mengoreksi dan mencari inisiatif terhadap jalannya seluruh kegiatan pendidikan yang dilaksanakan di lingkungan sekolah. Namun dalam menerapkan kepemimpinan yang berkualitas demi mewujudkan tujuan pendidikan dan manajemen mutu pendidkan, ada faktor ada banyakfaktor yang menghambat dan mendukung proses tersebut :

a. Faktor-Faktor Pendukung

1) Gotong Royong dan Kekeluargaan

Gotong royong dan kekeluargaan dapat dikembangkan untuk terwujudnya visi dan menjadi aksi nyata. Kondisi ini dapat ditumbuhkan oleh pengawas dengan bekerja sama dan mempererat hubungan sekolah dengan masyarakat lingkungan sekolah dan dunia kerja, sehingga dapat dimanfaatkan kepala sekolah untuk memperkenalkan program-program sekolah kepada masyarakat dan dunia kerja, terutama dalam penerapan mutu pendidkan.
2) Memberikan Kesempatan Kepada Guru Dalam Kegiatan Diklat Peningkatan profesi

Pengembangan diri adalah upayaupaya untuk meningkatkan profesionalisme diri agar memiliki kompetensi yang sesuai dengan peraturan perundang- undangan agar mampumelaksanakan tugas pokok dan kewajibannya dalam pembelajaran/pembimbingan termasuk pelaksanaan tugas-tugas tambahan yang relevan dengan fungsi sekolah/ madrasah. Kegiatan pengembangan diri terdiri dari diklat fungsional dan kegiatan kolektif guru untuk mencapai dan/atau meningkatkan kompetensi profesi guru yang mencakup: kompetensi pedagogis, kepribadian, sosial, dan professional. Diklat fungsional adalah kegiatan guru dalam mengikuti pendidikan atau latihan yang bertujuan untuk mencapai standar kompetensi profesi yang ditetapkan dan/atau meningkatkan keprofesian untuk memiliki kompetensi di atas standar kompetensi profesi dalam kurun waktu tertentu. Sedangkan kegiatan kolektif guru adalah kegiatan guru dalam mengikuti kegiatan pertemuan ilmiah atau kegiatan bersama yang bertujuan untuk mencapai standar atau di atas standar kompetensi profesi yang telah ditetapkan.

3) Memfasilitasi Segala Kegiatan Sekolah

Kepala sekolah yang profesional dalam paradigma baru manajemen pendidikan harus memberikan dampak positif dan perubahan yang mendasar dalam pembaharuan sistem pendidikan di sekolah, dampak tersebut antara lain terhadap efektifitas pendidikan, kepemimpinan sekolah yang kuat, pengelola sumber daya kependidikan yang efektif berorientasi pada penerapan mutu, team work yang kompak, 
cerdas dan dinamis, kemandirian, partisipatif dengan warga sekolah dan lingkungan masyarakat, keterbukaan, manajerial, inovatif, evaluasi dan perbaikan berkelanjutan, responsif, dan antisipasi terhadap kebutuhan serta akuntabilitas.

b. Faktor Pengahambat

Banyak faktor penghambat tidak tercapainya kualitas kepemimpinan seorang kepala sekolah seperti proses pengangkatannya tidak transparan, rendahnya mental kepala sekolah yang ditandai dengan kurangnya motivasi dan semangat serta kurangnya disiplin dalam melakukan tugas dan seringnya datang terlambat, wawasan kepala sekolah yang masih sempit serta banyak faktor lain yang menghambat kinerja seorang kepala sekolah untuk meningkatkan kualitas pendidikan pada lembaga yang dipimpinnya.

1) Kurangnya Motivasi dan Semangat Kepala Sekolah

Rendahnya mental kepala sekolah yang ditandai dengan kurangnya motivasi dan semangat serta kurangnya disiplin dalam melakukan tugas dan seringnya datang terlambat, yang menghambat kinerja seorang kepala sekolah untuk meningkatkan kualitas pendidikan pada lembaga yang dipimpinnya.

2) Kurangnya Kepemimpinan Kepala Sekolah

Kurangnya wawasan kepemimpinan berkaitan dengan masalah dan tantangan yang harus dihadapi para kepala sekolah dalam era globalisasi sekarang ini, dimana kemajuan ilmu pengetahuan dan teknologi berlangsung begitu cepat. Begitu cepatnya kemajuan ilmu pengetahuan dan teknologi sehingga menyulitkan sebagaian kepala sekolah dalam menghasilkan lulusan untuk bersaing di era global. Kondisi tersebut dapat disebabkan oleh kepala sekolah yang kurang membaca buku, kurang mengikuti perkembangan, jarang mengikuti seminar yang berhubungan dengan pendidikan.

3) Kurangnya Sarana dan Prasarana Kurangnya sarana dan parasarana pendidikan dapat menghambat kepala sekolah dalam menerapkan manajemen mutu pendidikan. Hal tersebut berkaitan dengan kemampuan pemerintah dalam melengkapi sarana dan prasarana untuk melengkapi yang masih kurang. Sarana adalah segala sesuatu yang mendukung secara langsung terhadap kelancaran proses kegiatan pendidikan, misalnya sebagai media pembelajaran, alatalat pelajaran, perlengkapan sekolah dan lain sebagainya. Sedangkan prasarana adalah segala sesuatu yang secara tidak langsung dapat mendukung keberhasilan suatu proses pembelajaran, misalnya jalan menuju sekolah, penerangan sekolah, kamar mandi sekolah, dan lain sebagainya. Sarana dan prasarana pendidikan adalah semua benda bergerak dan tidak bergerak yang dibutuhkan untuk menunjang penyelenggaraan kegiatan belajar mengajar, baik secara langsung maupun tidak langsung agar tujuan pendidikan tersebut dapat tercapai.

4) Rendahnya Sikap Mental

Rendahnya sikap mental kepala sekolah dalam menerapkan manajemen mutu pendidikan di SMP Negeri 2 Arungkeke antara lain kurang disiplin dalam melaksanakan tugas, kurang motivasi dan semangat kerja, serta sering datang terlambat, sehingga kondisi tersebut dapat menghambat kepala sekolah dalam menerapkan manajemenmutu pendidkan.

Mengenai analisis peran kepemimpinan kepala sekolah dalam menerapkan manajemen mutu pendidikan di SMP Negeri 2 Arungkeke Kabupaten 
Jeneponto, berikut peneliti mendeskripsikan pembahasan terkait kreativitas kepala sekolah menurut hasil penelitian di lokasi.

1. Peran Kepala Sekolah dalam Menerapkan Manajemen Mutu Pendidikan di SMP Negeri 2 Arungkeke, Kab. Jeneponto

Peran kepemimpinan kepala sekolah dalam menerapkan manajemen mutu pendidikan di SMP Negeri 2 Arungkeke sebagai berikut: 1) Kepala sekolah harus memiliki strategi yang tepat dalam memimpin lembaga pendidikan serta mengarahkan dan membimbing guruguru agar bertanggung jawab dan berpartisipasi secara aktif pada usaha sekolah dalam rangka mencapai tujuan sekolah. 2) Kepala sekolah harus mampu menerapkan manajemen kepemimpinan yang profesioal serta membina dan memupuk kerja sama dalam melibatkan guru untuk memajukan dan melaksanakan programprogram sekolah.

2. Faktor Pendukung dan Penghambat Kepala Sekolah dalam Menerapkan Manajemen Mutu Pendidikan di SMP Negeri 2 Arungkeke, Kab. Jeneponto

\section{a. Faktor Pendukung}

Faktor pendukung kepala sekolah dalam menerapkan manajemen mutu pendidikan di SMP Negeri 2 Arungkeke yaitu gotong royong dan kekeluargaan yang dikembangkan untuk terwujudnya visi dan menjadi aksi nyata. Kondisi ini dapat ditumbuhkan oleh pengawas dengan bekerja sama dan mempererat hubungan sekolah dengan masyarakat lingkungan sekolah dan dunia kerja, sosialisasi penerapankualitas pendidikan, memberikan kesempatan kepada guru dalam kegiatan diklat penerapan profesi, memfasilitasi segala kegiatan sekolah.

Kepala sekolah harus mampu menciptakan sikap gotong royong dan kekeluargaan terhadap semua elemen sekolah dengan bekerja sama dan mempererat hubungan dan komunikasi antara pihak sekolah dengan pengawas, masyarakat lingkungan sekolah, dan instansi lain untuk memperkenalkan program kegiatan sekolah untuk mewujudkan visi dan misi sekolah terutama dalam meningkatkan mutu pendidikan. Budaya dan iklim kerja yang kondusif akan memungkinkan setiap guru dan tenaga kependidikan lebih termotivasi untuk menunjukkan kinerjanya, yang disertai usaha untuk meningkatkan kompetensinya. Oleh karena itu, dalam upaya menciptakan budaya dan iklim kerja yang kondusif, kepala sekolah harus menciptakan suasana kekeluargaan sehingga semua kegiatan yang dilakukan menarik dan menyenangkan.

\section{b. Faktor Penghambat}

Faktor penghambat kepala sekolah dalam menerapkan manajemen mutu pendidikan di SMP Negeri 2 Arungkeke yaitu kurangnya wawasan kepala sekolah, rendahnya mental kepala sekolah yang ditandai dengan kurangnya motivasi dan semangat serta kurangnya disiplin dalam melakukan tugas dan seringnya datang terlambat, kurangnya kemampuan kepemimpinan kepala sekolah, dan kurangnya penguasaan IT yang menghambat kinerja seorang kepala sekolah untuk meningkatkan kualitas pendidikan pada lembaga yang dipimpinnya. Selain itu, faktor penghambat lainnya adalah Sarana dan 
prasarana merupakan faktor pemandu pelaksanaan proses pembelajaran, pengajaran dan penilaian untuk membantu mencapai hasil belajar yang diharapkan.

Ketika sarana dan prasarana lengkap, maka proses belajar mengajar akan berlangsung secara efektif dan efisien. Sebagai contoh, ruang belajar yang nyaman akan membuat peserta didik betah dalam proses belajar mengajar, tetapi ruang belajar yang sempit, pengap akan membuat peserta didik tidak nyaman dalam proses belajar mengajar sehingga tidak bisa mencapai tujuan pembelajaran yang diharapkan. Sarana dan prasarana berupa media pembelajaran menjadi salah satu unsur penunjang utama dalam keberhasilan pendidikan,dengan media yang lengkap,akan membuat peserta didik lebih bersemangat dan termotivasi dalam mengikuti pembelajaran, sehingga tujuan pembelajaran dapat dicapai. Selain itu, guru akan lebih mudah dalam menyampaikan pembelajaran.

\section{KESIMPULAN}

Peran kepemimpinan kepala sekolah dalam menerapkan manajemen mutu pendidikan di SMP Negeri 2 Arungkeke, yaitu pertama kepala sekolah sebagai pemimpin, harus memiliki strategi yang tepat dalam meningkatkan manajemen mutu pendidikan disekolah diantaranya kepala sekolah mempunyai peran sebagai edukator, manajerial dan administrator. Kepala sekolah diharapkan dapat menerapkan manajemen kepemimpinan yaitu kepala sekolah sebagai leader, supervisor, motivator, dan inovator bagi seluruh elemen sekolah. Kemudian faktor faktor pendukung kepala sekolah dalam menerapkan manajemen mutu pendidikan di SMP Negeri 74
2 Arungkeke yaitu gotong royong dan kekeluargaan yang dikembangkan untuk terwujudnya visi dan menjadi aksi nyata, memberikan kesempatan kepada guru dalam kegiatan diklat peningkatan profesi dan memfasilitasi kegiatan yang dilaksanakan disekolah. Faktor penghambat kepala sekolah dalam menerapkan manajemen mutu pendidikan di SMP Negeri 2 Arungkeke yaitu kurangnya motivasi dan semangat kepala sekolah dalam menjalankan tugasnya, kemampuan kepemimpinan kepala sekolah sangat rendah, sarana dan prasarana kurang memadai, serta rendahnya sikap mental kepala.

\section{DAFTAR PUSTAKA}

Nuril Mufidah \& Intan Izha Rohima. "Pengajaran Kosa Kata Untuk Mahasiswa Kelas Intensif Bahasa Arab: Vocabulary Teaching for Arabic Intensive Class." Uniqbu Journal of Social Sciences, vol. 1, no. 1, 2020, pp. 13-24, doi:10.47323/ujss.v1i1.7.

Abd. Ghofur, Isu-isu Pembelajaran Sastra, 1st ed., vol. 1. Pamekasan: Stain pmk press, 2010.

A. Ghofur, "CRITICAL DISCOURSE ANALYSIS OF POWER RELATION ON THE LIFE OF DAVID GALE FILM ON NORMAN FAIRCLOUGH PERSPECTIVE".

A. Ghofur, "How to increase Speaking Ability." https://scholar.google.com/citations?view_op =view_citation $\&$ hl=en\&user=9iU_f90AAA AJ\&cstart $=20 \&$ pagesize $=80 \&$ alert_preview _top_rm=2\&citation_for_view=9iU_f90AA AAJ:bEWYMUwI8FkC (accessed Jan. 11, 2022).

A. Ghofur, "DISCOURSE ANALYSIS: SOME CONCEPTUAL REMARKS ON PRAGMATICS AND RHETORIC," OKARA J. Bhs. Dan Sastra, vol. 5, no. 2, 2011, Accessed: Apr. 04, 2017. [Online]. Available:

http://www.ejournal.stainpamekasan.ac.id/in dex.php/okara/article/view/505

A. Ghofur, "READING OUR SOCIAL WORDS: UTILIZING NOVELS IN TEACHING SOCIOLOGY COURSES," OKARA J. Bhs. Dan Sastra, vol. 6, no. 1, 2012. 
A. Ghofur, “ANALISIS RAGAM TUTURAN PARA PELAKU PASAR KABUPATEN PAMEKASAN (Studi Sosiolinguistik Penggunaan Variansi Sapaan)," NUANSA J. Penelit. Ilmu Sos. Dan Keagamaan Islam, vol. 10, no. 2, 2013, Accessed: Apr. 04, 2017. [Online]. Available: http://ejournal.stainpamekasan.ac.id/index.ph p/nuansa/article/view/171/162

A. Ghofur, "HOW SFG INCREASE STUDENTS ABILITY TO PRODUCE AND ANALYSE TEXT MEDIA," OKARA J. Bhs. Dan Sastra, vol. 7, no. 1, 2013.

A. Ghofur, Madurese and English Morphology [The Process \& Diffrences]. Surabaya: Pena Salsabila, 2013.

A. Ghofur, "Analisis Dekonstruksi Tokoh Takeshi Dan Mitsusaburo Dalam Novel Silent Cry Karya Kenzaburo Oe Perspektif Jacques Derrida," NUANSA J. Penelit. Ilmu Sos. Dan Keagamaan Islam, vol. 12, no. 2, pp. 234257, 2015.

A. Ghofur, "CREATIVE TEACHING," OKARA J. Bhs. Dan Sastra, vol. 6, no. 2, 2017.

A. Ghofur, Representasi Entitas Ghuruh: Makna \& Perilaku bagi Masyarakat Madura Perspektif Interaksionisme Simbolik. Pamekasan: iainmadura press, 2020.

S. Hadi, A. Ghofur, and Humaidy, Moh Ali, Materi Pembekalan Kuliah Pengabdian Pada Masyarakat Perspektif IntegrasiInterkoneksi PAR dan POSDAYA Masjid. Yogyakarta: Pustaka Nusantara, 2014.

J. Jamaluddin and A. Ghofur, "An Analysis of Educational Values in 'Totto-Chan: The Little Girl at the Window' by Tetsuko Kuroyanagi Based on Paulo Freire's Perspective," PANYONARA J. Engl. Educ., vol. 2 , no. 1 , pp. 31-48, 2020.

M. Gofur, "Lecturer's Nonverbal Communication attitude in Classroom: Its Meaning for College Sudent," ELITE J., vol. 1, no. 1, pp. 35-42, 2019.

E. rabbiyanty, A. Ghofur, and A. Wafi, "MAXIMIZING THE USE OF WHATSAPP IN ENGLISH REMOTE LEARNING TO PROMOTE STUDENTS'ENGAGEMENT AT MADURA."

https://scholar.google.com/citations?view_op =view_citation\&hl=en\&user=9iU_f90AAA AJ\&alert_preview_top_rm=2\&citation_for_ view=9iU_f90AAAAJ:pqnbT2bcN3wC (accessed Jan. 11, 2022).

A. Asrifan and A. Ghofur, "THE USE OF READING CIRCLES IN INCREASING STUDENTS SPEAKING ABILITY AT THE
ELEVENTH GRADE SMK NEGERI 1 PANCARIJANG."

https://scholar.google.com/citations?view_op =view_citation $\&$ hl=en\&user=9iU_f90AAA AJ\&alert_preview_top_rm=2\&citation_for_ view=9iU f90AAAAJ:9ZIFYXVOiuMC (accessed Jan. 11, 2022).

A. Asrifan and A. Ghofur, "TALK, ACTION, SILENCE, INTERRUPTION AND THEIR IMPLICATIONS IN BUGINESE SOCIETY (SOPPENG REGENCY)." https://scholar.google.com/citations?view_op =view_citation\&hl=en\&user=9iU_f90AAA AJ\&alert_preview_top_rm=2\&citation_for_ view=9iU_f90AAAAJ:blknAaTinKkC (accessed Jan. 11, 2022).

A. Ghofur, "Study On Modalities of Hillary Clinton Debate on United States President Election on Hallidays' Systemic Functional Linguistic Analysis."

https://scholar.google.com/citations?view_op =view_citation\&hl=en\&user=9iU_f90AAA AJ\&alert_preview_top_rm=2\&citation_for_ view=9iU_f90AAAAJ:M3ejUd6NZC8C (accessed Jan. 11, 2022).

N. Aeni, B. Jabu, M. A. Rahman, H. Ismail, and S. Z. Bin-Tahir, "The Students' Needs in Maritime English Class at Ami Aipi Makassar, Indonesia," J. Lang. Teach. Res., vol. 9, no. 6, pp. 1284-1292, 2018.

Albana, H. H., Marzuki, A. G., Alek, A., \& Hidayat, D. N. (2020). Cohesive Devices in Student's Writing (A Discourse Analysis on Argumentative Text). Jurnal Pendidikan Humaniora, 8(1), 6-11.

Alek, A., Marzuki, A. G., Farkhan, M., \& Deni, R. (2020). Self-Assessment in Exploring EFL Students' Speaking Skill. Al-Ta lim Journal, 27(2), 208-214.

Alek, A., Marzuki, A. G., Farkhan, M., Surahman, D., Daryanto, D., \& Febrianto, S. (2020). Computer Based Testing in Senior High School on National Examination. Indonesian Journal of Learning Education and Counseling, 2(2), 204-210.

Alek, A., Marzuki, A. G., Hidayat, D. N., \& Sari, E. N. A. (2020). A Critical Discourse Analysis of song "Look What You Made Me Do" by Taylor Swift. Eralingua: Jurnal Pendidikan Bahasa Asing dan Sastra, 4(2), 154-161.

Alek, A., Marzuki, A. G., Hidayat, D. N., Islamiati, F. A., \& Raharjo, A. R. (2020). "Why She Disappeared"'(A Study of Illeism in Poetic Discourse). Ethical Lingua: Journal of Language Teaching and Literature, 7(2), 447453. 
Bin Tahir, S. Z. (2017). Multilingual teaching and learning at Pesantren Schools in Indonesia. Asian EFL Journal, 89, 74-94.

Bin-Tahir, S., Hanapi, H., Mufidah, N., Rahman, A., \& Tuharea, V. U. (2019). Revitalizing The Maluku Local Language In Multilingual Learning Model. INTERNATIONAL JOURNAL OF SCIENTIFIC \& TECHNOLOGY RESEARCH, 8(10).

Bin-Tahir, S. Z., \& Rinantanti, Y. (2016). Multilingual lecturers' competence in english teaching at the university of Iqra Buru, Indonesia. Asian EFL Journal, 5, 79-92.

Bin Tahir, S. Z. (2015). Multilingual behavior of Pesantren IMMIM students in Makassar. Asian EFL Journal, 86, 45-64.

Bin Tahir, S. Z. (2015). The attitude of Santri and Ustadz toward multilingual education at Pesantren. International Journal of Language and Linguistics, 3(4), 210-216.

Saidna Z, B. T., Haryanto, A., Syarifuddin, D., \& Yulini, R. (2017). Multilingual Instructional Model of Pesantren Schools in Indonesia. Journal of Language Teaching and Research, 8(6), 1210-1216.

Bin-Tahir, S. Z., Atmowardoyo, H., Dollah, S., Rinantanti, Y., \& Suriaman, A. (2018). MULTILINGUAL AND MONOMULTILINGUAL STUDENTS'PERFORMANCE IN ENGLISH SPEAKING. Journal of Advanced English Studies, 1(2), 32-38.

Bin-Tahir, S. Z., Suriaman, A., \& Rinantanti, Y. (2019). Designing English Syllabus for Multilingual Students at Pesantren Schools. Asian EFL Journal, 23(3.3), 5-27.

TAHIR, S. Z. A. B. (2017). Pengembangan Materi Multibahasa untuk Siswa Pesantren (Doctoral dissertation, Pascasarjana).

Bin-Tahir, S. Z., Atmowardoyo, H., Dollah, S., \& Rinantanti, Y. (2017). Multilingual learning program: pesantren students' perceptions of the multilingual simultaneous-sequential model. JELE (Journal Of English Language and Education), 3(2), 44-53.

Bin Tahir, S. Z. (2015). Multilingual Education in Pesantren Context. Yogyakarta: Deepublish.

Bin-Tahir, S. Z., Hanapi Hanapi, I. H., \& Suriaman, A. (2020). Avoiding Maluku Local Languages Death Through Embedded Multilingual Learning Model: Menghindari Kematian Bahasa Daerah Maluku melalui Model Pembelajaran Embedded Multilingual. Uniqbu Journal of Social Sciences, 1(1), 53-60.

Bin-Tahir, S. Z., Suriaman, A., Hanapi, H., Iye, R., \& Umanailo, M. C. B. (2020). Development of Buru Local Language Conversation.
Bin-Tahir, S. Z. (2015). Multilingual Teaching And Learning At Pesantren.

Tahir, S. Z. B., Atmowardoyo, H., \& Dollah, S. (2018). Belajar Berbicara Multibahasa Uuntuk Santri Pesantren. Deepublish.

Bin-Tahir, S., Hanapi, H., Mufidah, N., Rahman, A., \& Tuharea, V. U. (2019). Revitalizing The Maluku Local Language In Multilingual Learning Model. INTERNATIONAL JOURNAL OF SCIENTIFIC \& TECHNOLOGY RESEARCH, 8(10).

Tuharea, V. U., Tahir, S. Z. B., Ami, I. S. O., \& Rahman, A. (2020). Buru Language Conservation Through Sustainable Mulok Learning In Buru Regency:(Konservasi Bahasa Buru melalui Pembelajaran Mulok Berkelanjutan di Kabupaten Buru). Uniqbu Journal of Social Sciences, 1(2), 49-55.

Bin-Tahir, S. Z., \& Hanapi, H. (2020). Designing the Indonesian Local Language Learning in English Teaching at the Multilingual Classroom Context. Asian EFL Journal, 27(32), 108-120.

Bin-Tahir, S. Z., Tenriawali, A. Y., Umanailo, M. C. B., Hasyim, M., Latjuba, A. Y., \& Abbas, A. (2021). Designing English Teaching Model at the Remote Area Schools of Maluku in Covid19 Pandemic Situation. In Proceedings of the International Conference on Industrial Engineering and Operations Management (pp. 3933-3939).

Tahir, S. Z. B. (2021, March). Designing English Teaching Model at the Remote Area Schools of Maluku in Covid-19 Pandemic Situation. In Proceedings of the 11th Annual International Conference on Industrial Engineering and Operations Management. Universitas Iqra Buru.

Fatimah, A. S., \& Santiana, S. (2017). Teaching in $21^{\text {st }}$ century: Students-teachers' perceptions of technology use in the classroom. Script Journal: Journal of Linguistic and English Teaching, 2(2), 125.

Fatimah, A. S., Santiana, S., \& Saputra, Y. (2019). Digital Comic: An Innovation of Using Toondoo as Media Technology for Teaching English Short Story. English Review: Journal of English Education, 7(2), 101-108.

Fatimah, S. A., S, S., \& Sulastri, F. (2021). JOURNAL OF LANGUAGE AND LINGUISTIC STUDIES. Learner's experience on the use of mobile device for autonomous listening: A narrative inquiry. Journal of Language and Linguistic Studies, 17(1), 193-204

Haucsa, G. M., Marzuki, A. G., Alek, A., \& Hidayat, D. N. (2020). Illocutionary Speech Acts 
Analysis in Tom Cruise's Interview. Academic Journal Perspective: Education, Language, and Literature, 8(1), 11-19.

Hidayati, A., \& Santiana, S. (2020). Promoting Cultural Awareness through Intercultural Listening Activities. Jurnal Tahuri, 17(2), 5362.

https://doi.org/10.30598/tahurivol17issue2pag e53-62.

Iftitah, A. N., Marzuki, A. G., \& Kuliahana, A. (2020). DEVELOPING VOCABULARY MASTERY THROUGH GUESSING WORDS GAME FOR THE SEVENTH GRADE STUDENTS OF SMP NEGERI 10 PALU. Datokarama English Education Journal, 1(1), 19-37.

Kuliahana, A., \& Marzuki, A. G. (2020). Repetition Technique in an EFL Speaking Class in Islamic Higher Education in Indonesia. Academic Journal Perspective: Education, Language, and Literature, 8(1), 20-28.

Marzuki, A. G. (2019). The Implementation of SQ3R Method to Develop Students' Reading Skill on Islamic Texts in EFL Class in Indonesia. Register Journal, 12(1), 49-61.

Marzuki, A. G. (2019). The Roles of School Principal Leadership in Developing English Teachers' Creativities in Palu. Al-Ta lim Journal, 26(3), 267-279.

Marzuki, A. G. (2019). Utilizing Recorded English Dialogues in Teaching English Word Stress to Islamic Higher Education Students in Indonesia. Jurnal Pendidikan Islam, 5(1), 5364.

Marzuki, A. G., \& Kuliahana, A. (2021). Using Language Games to Enhance EFL Students' Speaking Skill in Indonesia. Al-Ta lim Journal, 28(3), 213-222.

Marzuki, A. G., Alim, N., \& Wekke, I. S. (2018). Improving the reading comprehension through cognitive reading strategies in language class of coastal area in indonesia. In IOP Conference Series: Earth and Environmental Science, 156(1), 012050). IOP Publishing.

Marzuki, A. G., Amelia, Y., \& Syam, H. (2021). THE EFFECT OF ANXIETY TOWARD STUDENTS'LEARNING MOTIVATION OF THE ELEVENTH GRADE AT SMAN 4 PALU. Datokarama English Education Journal, 2(1), 49-57.

Marzuki, A. G., Santiana, A. K., Alek, N. F., Darmawati, B., \& Bin-Tahir, S. Z. The Teaching of EFL Vocabulary through Anticipatory Learning Strategy in Islamic Higher Education Context in Indonesia.

Marzuki, A.G. (2016b). Utilizing cooperative learning in islamic college students' classroom, IJEE (Indonesian Journal of English Education), 3(2), 123-139.

Marzuki, A.G. (2017). Developing speaking skill through oral report in an efl class in indonesia, Al-Ta'lim Journal, 24(3), 243-254.

Nashirudin, M., \& Universal, K. H. (2013). Kajian atas Sistem dan Prospeknya di Indonesia. Semarang: El-Wafa.

Hasan, S., \& Nasma, A. (2008). Let's talk about love. Solo: Tiga Serangkai.

Nugroho, B. S., El Widdah, M., \& Hakim, L. (2020). Effect of organizational citizenship behavior, work satisfaction and organizational commitment toward Indonesian School Performance. Systematic Reviews in Pharmacy, 11(9), 962-971.

Nashirudin, M. (2019). Talîl al-Ahkâm dan Pembaruan Ushul Fikih. AHKAM: Jurnal Ilmu Syariah, 15(1).

Nashirudin, M., Hasan, M. A. S., \& Ag, M. (2009). Poros-Poros Ilahiyah Perempuan dalam Lipatan Pemikiran Muslim. Surabaya: Jaring Pena.

Nashirudin, M. (2016). Pandangan Majlis Tafsir AlQur'an (MTA) tentang Makanan Halal dan Haram (Kajian Usul Fikih). Al-Manahij: Jurnal Kajian Hukum Islam, 10(2), 235-252.

Amalina, N. H., \& Nashirudin, M. (2017). Analisis Proses Pembelajaran Bahasa Arab pada Tingkat Tsanawiyah di Pondok Pesantren Ta'mirul Islam. Jurnal Tatsqif, 15(2), 173190.

Nashirudin, M. (2017). Fatwa MUI Bidang Ibadah dan Perannya dalam Kehidupan Berbangsa dan Bernegara. International Islamic Conferernce on MUI Studies. Jakarta: MUI, 553

Nashirudin, M. (2015). Perbedaan dalam Furã ${ }^{\mathrm{TM}} €$ Тм Fiqhiyyah sebagai Akibat Perbedaan dalam Usã ${ }^{\mathrm{TM}} l$ Al-fiqh. None.

Kasdi, A., Nashirudin, M., Farida, U., \& Praatmana, N. D. (2021). Potential of Kudus as a New International Pilgrimage Destination in Indonesia: Halal Tourism Optimising Local Wisdom. International Journal of Religious Tourism and Pilgrimage, 9(1), 9.

Haris, H., \& Nashirudin, M. (2019). Lombok as an Indonesian halal travel destination. Shirkah: Journal of Economics and Business, 4(3).

Ibrahimy, A. A., Nawawi, N., \& Nashirudin, M. (2020). Kriteria Kafa'ah Dalam Perkawinan: Antara Absolut-Universal Dan RelatifTemporal. Al-Ahkam Jurnal Ilmu Syari'ah dan Hukum, 5(2).

Nashirudin, M. (2017). Interaksi Simbolis Pondok Pesantren Salafi dan Masyarakat. Epistemé: Jurnal Pengembangan Ilmu Keislaman, 12(1), 141-167. 
Yahya, I., Nashiruddin, M., \& Aziz, A. (2016). Konsep Jihad 'Abdullah B. Al-mubarak dan Jihad Global. MISYKAT: Jurnal Ilmu-ilmu Al-Quran, Hadist, Syari'ah dan Tarbiyah, 1(1), 147-180.

Nashiruddin, M., \& El Muhammadi, A. (2016). Korelasi kreativitas dan motivasi kerja guru terhadap peningkatan mutu pembelajaran. IJER (Indonesian Journal of Educational Research), 1(1), 51-57.

Nashiruddin, M. (2012). Tinjauan fikih dan astronomis penyatuan matla': menelusuri pemikiran MS Odeh tentang ragam penyatuan matla'. Ijtihad: Jurnal Wacana Hukum Islam dan Kemanusiaan, 12(2), 179192.

Nashirudin, M. (2012). Kalender Hijriyah Universal, Kajian atas pemikiran MS Odeh dan prospeknya di Indonesia. Disertasi (Program Doktor IAIN Walisongo).

Nashirudin, M. (2011). Sistem penanggalan Hijriah Mohammad Shawkat Odeh. Ijtihad: Jurnal Wacana Hukum Islam dan Kemanusiaan, 11(2), 199-217.

Nashirudin, M., \& Universal, K. H. (2009). Menelusuri Pemikiran Muhammad SyaukatOdeh, makalah disampaikan dalam acara. In Prosidings Seminar Nasional Hilal 2009: Mencari Solusi Kriteria Visibilitas Hilal dan penyatuan Kalender Islam dalam Perspektif Sains dan Syariah.

Santiana \& Fatimah, A. S. (2017). PREZI, CLOUDBASED PRESENTATION, FOR TEACHING: HOW IS IT INTERESTING? Journal of English Education, Literature, and Culture_EduLite, 2(2), 445-456. http://jurnal.unissula.ac.id/index.php/edulite/ar ticle/view/ 1196/125

Santiana, S., Lesmana, D. S., Marzuki, A. G., \& Erizar, E. (2021, December). AN INSIGHT OF ANITALES APPS PERCEIVED BY DIGITAL STORYTELLING STUDENTS. In Proceeding of International Conference on Islamic Education (ICIED) (Vol. 6, No. 1, pp. 23-30).

Santiana, S., Silvani, D., \& Ruslan. (2021). Optimizing LMS CANVAS for Interactive Online Learning Perceived by the Students. Journal of English Education and Teaching (JEET), 5(4), 529-543.

Santiana, S., Pujasari, R. S., \& Fatimah, A.S. (2021). Blended Learning Strategy: Alternatif Pembelajaran Toefl Bagi Guru-Guru Mgmp Non-Bahasa Inggris. Jurnal Inovasi, 1(2020), 144-161.

https://ejournal.unib.ac.id/index.php/jurnalino vasi/article/view/15883.
Widya, T., Fatimah, A. S., \& Santiana. (2020). Students' Feedback As a Tool for Reflection: a Narrative Inquiry of an Indonesian Pre-Service Teacher. Journal of Teaching \& Learning English in Multicultural Contexts (TLEMC), 4(1), $1-11$. http://jurnal.unsil.ac.id/index.php/tlemc/article/ view/1775

Muthmainnah, A. R., Atmowardoyo, H., Salija, K., \& Asrifan, A. (2020). Literary Work as Teaching Materials: A Study of Students and Lecturers Needs Analysis. Solid State Technology, 63(5), 394-407.

Asrifan, A., Muthmainnah, M., Al-Yakin, A., Sahabuddin, C., \& Haedar, H. (2018). THE CAUSE-EFFECT TECHNIQUE IN TEACHING RECOUNT WRITING. JOURNAL OF ADVANCED ENGLISH STUDIES, 1(2), 63-72.

Al Yakin, A., Sahabuddin, C., Rahayu, A., Fitrah, N., \& Arifin, M. (2020). Political Celebrification and Electability: A Study of Political Phenomena Imaging in Election Polewali Mandar District, West Sulawesi, Indonesia. Solid State Technology, 63(5), 632646.

Muthmainnah, M., Asrifan, A., Al Yakin, A., \& Sahabuddin, C. (2019, April). The use of dictogloss technique on ELT classroom: An experiment study of students listening comprehension. In PROCEEDINGS OF THE 65th TEFLIN INTERNATIONAL CONFERENCE (Vol. 65, No. 01).

Asrifan, A., Rinantanti, Y., Tang, S., \& Nadirah, N. (2019). THE 3-DIMENSION PICTURES IN INCREASING THE STUDENTS ABILITY AND INTEREST TO WRITE DESCRIPTIVE COMPOSITION. JOURNAL OF ADVANCED ENGLISH STUDIES, 2(1), 19-30.

Nadilla, T., Ulfah, A. K., Hayati, H., Midesia, S., \& Puspita, D. (2019, November). The Effect Of Leverage And Earning Per Share On Earning Management (A Study Of Companies Listed In Indonesia Stock Exchange). In ICASI 2019: Proceedings of The 2nd International Conference On Advance And Scientific Innovation, ICASI 2019, 18 July, Banda Aceh, Indonesia (p. 164). European Alliance for Innovation.

Ulfah, A. K. (2019). Double Entry Bookkeeping Dalam Akuntansi. J-ISCAN: Journal of Islamic Accounting Research, 1(1), 1-14.

Ulfah, A. K., Fernanda, D., Rahmaniar, R., Mediyanti, S., Agustina, A., Azlina, A., \& Andina, A. (2019, February). Analisis Kemampuan Pembiayaan Keuangan Pemerintah Provinsi Aceh Setelah Penerapan 
Revisi UU Tentang Otonomi Daerah. In Seminar Nasional Teknologi Komputer \& Sains (SAINTEKS) (Vol. 1, No. 1).

Nurlinda, N., Napitupulu, I. H., Wardayani, W., Azlina, A., Andina, A., Ulfah, A. K., \& Supriyanto, S. (2019). Can E-Commerce Adoption Improve SME's Performance?(Case Studies on Micro, Small and Medium Enterprises with Gojek Services in Indonesia). In Proceedings of the Third Workshop on Multidisciplinary and Its Applications, WMA-3.

Basri, H., Ulfah, A. K., \& Majid, M. (2017). The implementation of good corporate governance (GCG) to improve service quality: the case of state-owned electricity company in Indonesia.

Ulfah, A. K. (2018). KINERJA PERSONIL PEMAKAI SISTEM INFORMASI AKUNTANSI SETELAH PELATIHAN SISTEM INFORMASI AKUNTANSI PADA POLDA ACEH. Jurnal Bis-A: Jurnal Bisnis Administrasi, 7(2), 40-46.

Fadhillah, N., Lubis, M. H., Sinar, T. S., \& Setia, E. (2019). Translation strategies used in Indonesian translation of Acehnese poem "Munajat Perempuan Sufi Aceh Pocut di Beutong.". International Journal of Innovation, Creativity and Change, 9(4), 172-182.

Khalsiah, R., Fadhillah, N., Praza, R., \& Desiariawati, N. (2018). An Analysis of Culture Value in Adat Bak Poe Teumeureuhom, Hukom Bak Syiah Kuala, qanun Bak Putro Phang, Reusam Bak Binatara. Indian Journal of Public Health, 9(12).

Lubis, M. H., \& Fadhillah, N. (2020). LOOKING FOR TRANSLATION OF MEANING OF WORDS QALA IN MATAN ARBA IN HADITH. Talent Development \& Excellence, 12(1).

Khalsiah, M., Apridar, N. F., \& Ratri Candrasari, J. (2020). Fiction and Nonfiction Novel: Characteristics Possessed To Allure The Reader. Journal of Talent Development and Excellence, 12(1), 2081-2088.

Lubis, M. H., Fadhillah, N., Candrasari, R., \& Rizki, D. (2020). Fiction and Nonfiction Novel: Characteristics Possessed To Allure The Reader. Talent Development \& Excellence, 12(1).

Aeni, N., Jabu, B., Rahman, M. A., Ismail, H., \& BinTahir, S. Z. (2018). The Students' Needs in Maritime English Class at Ami Aipi Makassar, Indonesia. Journal of Language Teaching and Research, 9(6), 1284-1292.

Aeni, N., Jabu, B., Rahman, M. A., \& Strid, J. E. (2017). English oral communication apprehension in students of Indonesian maritime. International Journal of English Linguistics, 7(4), 158-167.
Aeni, N., \& Panggua, S. (2017, July). A classroom action research at the second year students of indonesian maritime academy aipi makassar. In International Conference on Education, Science, Art and Technology (pp. 131-142).

Arsyad, U., Putranto, B., Aeni, N., Isnan, W., \& Hasnawir, H. (2019). Analysis of biogeophysics characteristics and discharge of Lompo Riaja Atas river and Lompo Riaja Bawah river, Ralla sub watershed. Jurnal Penelitian Kehutanan Wallacea, 8(1), 27-38.

Aeni, N., Fitriani, F., \& Fitri, N. (2019). The Use of Circle Games to improve the Mastery of English Vocabulary of the Indonesian Maritime Academy Students. Journal of Educational Science and Technology (EST), 5(3), 239-244.

Marani, I. N., Subarkah, A., \& Wijayanto, A. (2020). The use of computer mediated communication (cmc) In distance learning during covid-19 pandemic: pros and cons. The International Journal of Indian Psychology ISSN, 2348-5396.

Wijayanto, A. (2018). PENGARUH METODE GUIDED DISCOVERY, DAN METODE MOVEMENT EXPLORATION SERTA PERSEPSI KINESTETIK TERHADAP HASIL BELAJAR PUKULAN ATAS BULUTANGKIS PADA MAHASISWA IAIN TULUNGAGUNG. Halaman Olahraga Nusantara (Jurnal Ilmu Keolahragaan), 1(2), 160-176.

Wijayanto, A. (2018). Pengaruh Latihan Renang Teratur Dan Latihan Renang Tidak Teratur Terhadap Kadar Trigliserida Plasma Pada Rattus norvegicus. Biotropic The Journal of Tropical biology, 2(1), 24-40.

Wijayanto, A. (2021). BUNGA RAMPAI Kolaborasi Multidisiplin Ilmu Dalam Menghadapi Tantangan di Era New Normal.

Wijayanto, A., \& Khurniawan, A. W. (2021). BUNGA RAMPAI Strategi Pembelajaran Pendidikan Jasmani Olahraga Dan Kesehatan Selama Pandemi Covid-19.

Mayanto, A., Taufik, M. S., Wijayanto, A., Solahuddin, S., \& Taroreh, B. S. (2021). MODEL PEMBELAJARAAN JARAK PENDEK PADA SISWA SEKOLAH MENENGAH PERTAMA. Jurnal Kejaora (Kesehatan Jasmani Dan Olah Raga),6(1), 114-120.

Wijayanto, A. Budijanto. 2011. Software Sistem Informasi Penggunaan Energi dan Kebutuhan Kalori. Jurnal IPTEK Olahraga KEMENEGPORA, 13, 1411-0016.

Bin-Tahir, S. Z., Saidah, U., Mufidah, N., \& Bugis, R. (2018). The impact of translanguaging approach on teaching Arabic reading in a multilingual classroom. Ijaz Arabi Journal of Arabic Learning, 1(1). 
Febriani, S. R., Widayanti, R., Amrulloh, M. A., \& Mufidah, N. (2020). Arabic learning for elementary school during COVID-19 emergency in Indonesia. OKARA: Jurnal Bahasa dan Sastra, 14(1), 67-80.

Saidah, U., Bin-Tahir, S. Z., \& Mufidah, N. (2018). ARABIC TEACHERS'COMPETENCE: A CASE OF MADRASAH SCHOOLS IN MALUKU. Ijaz Arabi Journal of Arabic Learning, 1(2).

Mufidah, N., Firdaus, U. Z., \& Tahir, S. Z. B. (2018). Model Pengayaan Tutor Bahasa: Studi prelearning pada Shabahul Lughoh di Ma'had Sunan Ampel Al Aly. Jurnal At-Ta'dib $\mathrm{Vol}, 13(2)$.

Mufidah, N., \& Rohima, I. I. (2020). Pengajaran Kosa Kata Untuk Mahasiswa Kelas Intensif Bahasa Arab: Vocabulary Teaching for Arabic Intensive Class. Uniqbu Journal of Social Sciences, 1(1), 13-24.

Mufidah, N., Suryawati, D., Sa'adah, N., \& Tahir, S. Z. B. (2019). Learning Arabic writing skill based on digital products. Ijaz Arabi Journal of Arabic Learning, 2(2).

Mufidah, N., Salamah, U., Muthoharoh, I., \& Islamy, M. I. (2019). Hybrid learning dalam pembelajaran kosa kata bahasa Arab pada anak berbantuan media Al-Mutho. Al-Mudarris: Journal Of Education, 2(1), 40-52.

Mufidah, N., \& Tahir, S. Z. B. (2018). Empowering E-Learning As An Interactive Teaching For Arabic Learners. Lisanudhad, 5(2), 57-72.

Ummah, S. S., \& Wafi, A. (2017). Metode-Metode Praktis dan Efektif dalam Mengajar Al-Quran Bagi Anak Usia Dini. ACIECE, 2, 121-134.

Wafi, A. (2019). Using Games to Improve Students' Active Involvement in the Learning of English Syntax at IAIN Madura: An Autonomous Learning. OKARA: Jurnal Bahasa dan Sastra, 13(1), 107-120.

Wafi, A. (2011). Using the Think-Pair-Share Strategy to Increase Students' Active Involvement and to Improve Students' Speaking Ability at Islamic the University of Malang.(Thesis). DISERTASI dan TESIS Program Pascasarjana UM.

Rabbianty, E. N., \& Wafi, A. (2021). MAXIMIZING THE USE OF WHATSAPP IN ENGLISH REMOTE LEARNING TO PROMOTE STUDENTS'ENGAGEMENT AT MADURA. LET: Linguistics, Literature and English Teaching Journal, 11(1), 42-60.

Ratnawati, R., Wafi, A., \& Navlia, R. (2020). A Study Of English Songs On Teaching Vocabulary At Kindergaten Students Of Lembaga Pendidikan Islam Bustanuddin Galis Pamekasan. Kiddo: Jurnal Pendidikan Islam Anak Usia Dini, 1(2), 174-186.
Khulaisie, R. N., Hafizh, A. A., Wafi, A., \& Sofia, S. (2019). Achieving Harmony Through Progressive Islamic Dimensions in the Thinking of Abdullah Saeed. Islam Realitas: Journal of Islamic and Social Studies, 5(1), 1-11.

Utami, S., \& Wafi, A. (2020). MANAGEMENT OF EARLY CHILD'S CHARACTER DEVELOPMENT THROUGH HABITUATION AND EXEMPLARY IN KINDERGARTEN. Re-JIEM (Research Journal of Islamic Education Management), 3(2), 216-230.

Fadilah, F., \& Wafi, A. (2020, October). CREATING TEACHER AND STUDENTS-CENTERED ON TEACHING ENGLISH LANGUAGE BY USING ESP APPROACH AT NON-ENGLISH DEPARTMENT. In Proceedings of the 2nd International Conference on English Language Education (ICONELE) 2020.

Asrifan, A., Vargheese, K. J., Syamsu, T., \& Amir, M. (2020). ESP Course Design: The Need Analysis on Tourism Department in Indonesia Vocational High Schools. Journal of Advanced English Studies, 3(2), 69-77.

Apdy, A. P. R., \& Asrifan, A. (2019, April). The Chinese mime game in teaching vocabulary on EFL classroom. In Proceedings of the 65th TEFLIN International Conference (Vol. 65, No. 01).

Puasa, K., Asrifan, A., \& Chen, Y. (2017). Classroom talk in bilingual class interaction. Research in Pedagogy, 7(1), 106-121.

Nadirah, N., Asrifan, A., Vargheese, K. J., \& Haedar, H. (2020). INTERACTIVE MULTIMEDIA IN EFL CLASSROOM: A STUDY OF TEACHING READING COMPREHENSION AT JUNIOR HIGH SCHOOL IN INDONESIA. Journal of advanced english studies, 3(2), 131-145.

Asrifan, A., Zita, C. T., Vargheese, K. J., Syamsu, T., \& Amir, M. (2020). THE EFFECTS OF CALL (COMPUTER ASSISTED LANGUAGE LEARNING) TOWARD THE STUDENTS'ENGLISH ACHIEVEMENT AND ATTITUDE. Journal of advanced english studies, 3(2), 94-106.

Tang, S., Asrifan, A., Chen, Y., Haedar, H., \& Agussalim, M. (2019). The Humor Story in Teaching Reading Comprehension. Journal of advanced english studies, 2(2), 77-87.

Tilome, A. A., Agustang, A., Jasruddin, M. S., \& Asrifan, A. (2020). Social Exchange of Political Elites in the Regional Leader Election of Gorontalo Province, Indonesia. Solid State Technology, 63(5), 521-531.

Suriaman, A., Bin-Tahir, S. Z., \& Usman, S. (2019). Designing Web-Based English Listening 
Instruction: An Analysis of Indonesian University Student's Needs. Asian EFL Journl. Vol. 23 (3.3), 28-40.

Yusriadi, Y., bin Tahir, S. Z., Awaluddin, M., \& Misnawati, M. (2020). Poverty Alleviation through Social Entrepreneur. Journal of Education, Humaniora and Social Sciences (JEHSS), 3(2), 721-725.

Bin Tahir, S. Z., Iye, R., Tenriawali, A. Y., Karim, Z. Z. Z., \& Umanailo, M. C. B. (2020, March). Cia-cia vocational inventoryization in Buru district. In Proceedings of the International Conference on Industrial Engineering and Operations Management (No. 0, pp. 25092518).

Nagauleng, A. M., Waris, A. M., \& Bi-Tahir, S. Z. (2019, April). Psycho pedagogical aspects of EFL learners' performance: a case study at IAIN of Manado. In PROCEEDINGS OF THE 65th TEFLIN INTERNATIONAL CONFERENCE (Vol. 65, No. 01).

Tuharea, V. U., Tahir, S. Z. B., Ami, I. S. O., \& Rahman, A. (2020). Buru Language Conservation Through Sustainable Mulok Learning In Buru Regency:(Konservasi Bahasa Buru melalui Pembelajaran Mulok Berkelanjutan di Kabupaten Buru). Uniqbu Journal of Social Sciences, 1(2), 49-55.

Bin-Tahir, S. Z. (2020). The Role of Local Language in Intercultural Communication among Societies of Buru Island.

Misnawati, A. H., Rahman, Y. Y., Hutapea, R. H., \& Bin-Tahir, S. Z. (2021). Inhibiting Factors (Internal \& External) Implementation of the Family Hope Program (PKH) in Bone Regency. In Proceedings of the 11th Annual International Conference on Industrial Engineering and Operations Management Singapore.

Fatgehipon, A. H., \& Bin-Tahir, S. Z. (2019). Building students state defending awareness in preventing the radicalism. International Journal of Scientific \& Technology Research, 8(10), 3536-3539.

Susiati, S., Tahir, S. Z. B., Hajar, I., \& Tenriawali, A. Y. (2021). Optimalisasi Masyarakat Desa Namlea Dalam Menghadapi Tanggap Darurat Pandemi Covid-19. Journal of Community Dedication and Development (Pengabdian Kepada Masyarakat), 1(1), 50-59.

Misnawati, M., Abd Rasyid, J., Yusriadi, Y., Pengayoman, S. T. I. H., \& Bin-Tahir, S. Z. (2019). The Role of Family Hope Program Actor in Empowering Poor Society (Case Study of Bone Regency) Indonesia. Journal of Public Administration and Governance, 9(2), 359-366.

Reynilda, R., Zainal, H., Rijal, S., Yusriadi, Y., \& Tahir, S. Z. B. (2021, March). Licensing services in the era of the COVID-19 pandemic.
In Proceedings of the 11th Annual International Conference on Industrial Engineering and Operations Management (pp. 6322-6329). Universitas Iqra Buru.

Ansar, U. F., Yahya, M., Yusriadi, Y., \& Bin-Tahir, S. Z. Institutional Economic Analysis Of Bugis Merchants In The Inter-Island Trade.

Mulyana, Y., Akbar, Z., Zainal, H., Yusriadi, Y., \& Tahir, S. Z. B. (2021, March). High Domestic Violence during the Pandemic COVID-19. In Proceedings of the 11th Annual International Conference on Industrial Engineering and Operations Management (pp. 6283-6290). Universitas Iqra Buru.

Tahir, S. Z. B. (2021, March). Designing English Teaching Model at the Remote Area Schools of Maluku in Covid-19 Pandemic Situation. In Proceedings of the 11th Annual International Conference on Industrial Engineering and Operations Management. Universitas Iqra Buru.

Sadapotto, A., Hanafi, M., Bahang, D., Baharuddin, T., Tahir, S. Z. B., \& Yusriadi, Y. (2021). Investigating Celebritism Phenomenon on Twitter (Semiotics Analysis Trending Topic).Academy of Strategic Management Journal, 20, 1-16. 